Estudios Constitucionales, Año 8, No 2, 2010, pp. 359 - 388.

ISSN 0718-0195

Centro de Estudios Constitucionales de Chile Universidad de Talca

"El derecho internacional de los derechos humanos

desde la óptica de la Corte Suprema de Justicia de Argentina"

Víctor Bazán

\title{
EL DERECHO INTERNACIONAL DE LOS DERECHOS HUMANOS DESDE LA ÓPTICA DE LA CORTE SUPREMA DE JUSTICIA DE ARGENTINA
}

\section{The InTERnational Human Rights LaW FROM the STANDPOINT OF THE Supreme Court of Justice in Argentina}

\author{
VÍCTOR BAZÁN* \\ Profesor Titular de las asignaturas Derecho Constitucional \\ y Derecho Internacional Público de la Facultad de Derecho \\ y Ciencias Sociales de la Universidad Católica de Cuyo, Argentina \\ vicba2002ar@yahoo.com.ar
}

RESUMEN: El autor realiza un análisis de la trayectoria jurisprudencial de la Corte Suprema de Justicia argentina en torno al derecho internacional de los derechos humanos y su relación con el derecho interno, para señalar la paulatina metamorfosis que la doctrina judicial del Alto Tribunal ha venido experimentando en la materia.

Asimismo, examina el fuerte impacto que la reforma constitucional de 1994 ha provocado en el ámbito de los derechos humanos en el escenario jurídico argentino; la recepción en el contexto interno del control de convencionalidad establecido por la Corte Interamericana de Derechos Humanos; y la linea de seguimiento, no siempre homogénea, que exhibe la Corte Suprema respecto de las sentencias y opiniones consultivas de este tribunal interamericano, y de los pronunciamientos de la Comisión Interamericana de Derechos Humanos y de otros órganos cuasijurisdiccionales pertenecientes al esquema universal de protección de los derechos fundamentales.

ABSTRACT: The author analyzes the jurisprudential path of the Supreme Court of Justice in Argentina regarding to the International Human Rights Law and its relationship with Domestic Law, to mark the gradual metamorphosis that the judicial doctrine of the High Court has been experiencing in the matter.

He also examines the strong impact that the constitutional reform of 1994 has resulted in the field of human rights in the Argentine legal scenario, the reception at the national level of conventionality control established by the Inter-American Court of Human Rights, and the monitoring line, not always uniformly exhibited by the Supreme Court, regarding the judgments and advisory opinions of the Inter-

\footnotetext{
* Profesor Titular de las asignaturas Derecho Constitucional y Derecho Internacional Público de la Facultad de Derecho y Ciencias Sociales de la Universidad Católica de Cuyo (San Juan, Argentina). Fundador y actual Director del Instituto de Derecho Constitucional, Procesal Constitucional y Derechos Humanos de la misma Facultad. Profesor del Curso Intensivo de Posgrado de "Derecho Constitucional, Derecho Constitucional Procesal y Derechos Humanos" de la Facultad de Derecho de la Universidad de Buenos Aires (UBA). E-mail: vicba2002ar@yahoo.com.ar Recibido el 24 de agosto y aprobado el 22 de septiembre de 2010.
} 
American Court, the pronouncements of the Inter-American Commission of Human Rights and other quasi-judicial bodies belonging to the universal scheme of protection of fundamental rights.

PALABRAS CLAVE: Derecho internacional de los derechos humanos y derecho interno. Corte Suprema de Justicia argentina. Control de convencionalidad. Sentencias y opiniones consultivas de la Corte Interamericana de Derechos Humanos. Directivas de la Comisión Interamericana de Derechos Humanos. Otros órganos cuasijurisdiccionales del sistema universal de protección de los derechos humanos.

KEY WORDS: International Human Rights Law and Domestic Law. Argentina's Supreme Court of Justice. Control of conventionality. Judgments and advisory opinions of the Inter-American Court of Human Rights. Directives of the Commission on Human Rights. Other quasi-judicial bodies of the universal system of protection of human rights.

\section{PRELIMINAR}

En este trabajo nos proponemos analizar la doctrina de la Corte Suprema de Justicia de la Nación (CSJN) específicamente en torno al derecho internacional, de manera primordial respecto de los derechos humanos, y su relación con el derecho interno.

El tema es vasto y complejo, por lo que la tarea de sistematización jurisprudencial no será sencilla. De cualquier modo, intentaremos perfilar esquemáticamente -a modo de muestreo- algunos pronunciamientos significativos del Alto Tribunal argentino e identificaremos ciertos estándares que paulatinamente van configurándose en la materia.

\section{De Ciertos ELEMENTOS DE ANÁlisis PARA ENTENDER EL PROCESO DE EVOLUCiÓn JURISPRUdENCIAL DE LA CORTE SUPREMA EN LA MATERIA}

Como anuncio sintético y hasta rudimentario del nudo de esta contribución, podría afirmarse que existe una trilogía de factores relevantes, de la que no podría prescindirse en un intento de análisis como el que emprenderemos, que deja huella y marca rumbos en la conformación de la doctrina judicial de la CSJN y, por extensión (aunque no siempre ni con la intensidad deseable), de los tribunales inferiores:

1. El fallo recaído en la causa "Ekmekdjian c/ Sofovich", del 7 de julio de 1992, verdadero punto de inflexión en la temática que examinaremos, precedente que proporciona una mayor dosis de coherencia a la jurisprudencia del Alto Tribunal (en cuanto a la relación del derecho internacional convencional y el derecho interno), luego de diversas oscilaciones e inconsistencias hasta entonces experimentadas;

${ }^{1}$ Fallos, 315:1492. 
2. La reforma constitucional de 1994 que, fundamentalmente en el ámbito de los derechos humanos, ha provocado un fuerte impacto que conduce a la reinterpretación de determinadas categorías jurídicas en diferentes áreas del derecho público y del derecho privado, y a la re-significación de derechos, principios y valores a la luz del derecho internacional de los derechos humanos, y

3. La renovación parcial de la composición del Tribunal producida entre 2002 y 2004, que -al menos en el particular- ha propiciado en su seno la intensificación de una jurisprudencia activista y, en líneas generales, consistente con los requerimientos internacionales.

\section{BREVE EXAMEN DE ALGUNAS DOCTRINAS QUE PRETENDIERON INDAGAR SOBRE LAS RELACIONES DEL DERECHO INTERNACIONAL Y EL DERECHO INTERNO}

\section{Pórtico}

No pretendemos analizar pormenorizadamente aquí una disputa teórica-que hoy ha perdido buena parte de su valor calórico- entre las posiciones que en su momento pretendieron explicar las vinculaciones del derecho internacional como regulatorio de las relaciones entre los sujetos de la comunidad internacional, y los ordenamientos internos de los Estados.

Sólo a los efectos de la alusión que ineludiblemente deberá realizarse aquí respecto de las variaciones de las posturas que al respecto fue adoptando la CSJN en su trayectoria jurisprudencial, dedicaremos un breve espacio a describir el marco conceptual relativo a aquellas tesis que, en un acercamiento taxonómico primario, pueden escindirse en monistas, dualistas y coordinadoras o armonizantes.

Básicamente, el núcleo de discusión consistía en la búsqueda de respuesta a una doble interrogante: i) el modo como el derecho internacional se incorporaba al derecho interno; y ii) solventado tal interrogante inicial, la determinación de la jerarquía de las normativas en cuestión.

\section{2) Las tesis salientes sobre el punto}

\section{A) Dualismo}

Los dualistas más representativos fueron ANZILOTTI y TRIEPEL. Básicamente, esta teoría postulaba que no existía un único sistema jurídico, sino dos completamente separados e independientes (razón por la cual estas tesis se denominaban también pluralistas o de paralelismo jurídico): el derecho internacional y el derecho interno ${ }^{2}$.

\footnotetext{
${ }^{2}$ Ver, para ampliar, Díez de Velasco Vallejo, Manuel, Instituciones de Derecho Internacional Público, T. I, $8^{a}$ ed., Tecnos, Madrid, 1988, p. 165.
} 
Razonaban que uno y otro poseían distintas fuentes y regían diferentes ámbitos y sujetos, por lo que mientras el derecho internacional regulaba las relaciones entre Estados, el derecho interno gobernaba las relaciones entre particulares o entre el Estado y sus súbditos.

Como consecuencia de tal formulación teórica, una norma de derecho internacional debía ser transformada en norma de derecho interno para poder ser invocada y aplicada en el ordenamiento nacional, lo que llevaba a concluir que en caso de conflicto entre ellas esta última prevalecía sobre la de derecho internacional.

\section{B) Monismo}

Sus principales exponentes fueron KELSEN y Wenzel. Esencialmente, para los cultores de esta teoría las normas del derecho internacional y las del derecho interno formaban un único sistema jurídico. Si bien todos los monistas sostenían la unidad del ordenamiento jurídico, podían identificarse al interior de esta teoría aquellos que otorgaban preferencia al derecho nacional en relación con el derecho internacional (monismo con primacía en el derecho interno - WeNZEL-) y los que adjudicaban prevalencia al derecho internacional respecto del derecho interno (monismo con primacía en el derecho internacional-KELSEN, aunque en un principio había optado por la preeminencia del derecho interno sobre el internacional, mudando luego de opinión-).

Justamente respecto de KelSEN, explica PASTOR RidRuejo que en su concepción normativista todas las normas jurídicas derivaban su validez y fuerza obligatoria de otras normas superiores desde el punto de vista jerárquico, hasta llegar a la norma fundamental o Grundnorm. Si bien en 1926 KELSEN indicó que esta última podía ser ubicada en el derecho interno o en el derecho internacional, dependiendo de factores éticos o políticos, más tarde entendió que debía insertarse en el derecho internacional, tal como se aclaró en el párrafo anterior ${ }^{3}$.

A su tiempo, Verdross (discípulo de KeLSEN) interpretó que la norma que en definitiva fundamentaba todo el derecho se emplazaba en el ordenamiento internacional, siendo éste precisamente el que delegaba a favor de los Estados una determinada competencia legislativa dentro del marco de su libre apreciación ${ }^{4}$. De esta manera, el derecho internacional sería superior al derecho interno, la norma internacional no necesitaría de ninguna especie de acto de recepción para

\footnotetext{
${ }^{3}$ Pastor Ridruejo, José A., Curso de Derecho Internacional Público y Organizaciones Internacionales, $10^{\mathrm{a}}$ ed., Tecnos, Madrid, 2006, pp. 168-169.

${ }^{4}$ Verdross, Alfred, "Le Fondement du Droit Internacional", Recueil des Cours de l'Académie de Droit Internacional de La Haye, I, vol. 16, 1927, pp. 257 y ss.; cit. por Pastor Ridruejo, José A., ibid., p. 169 y nota 3 a pie de página.
} 
ser aplicada en los ordenamientos nacionales y prevalecería sobre éstos en caso de conflicto 5 .

\section{C) Doctrinas coordinadoras}

Con el correr del tiempo, dualistas y monistas fueron atenuando la intransigencia de sus argumentos y, si se quiere, efectuando concesiones recíprocas. Así, como puntualiza CARRILlo SALCEDO, los dualistas reconocieron que el Estado cuyo ordenamiento interno no cumpliera normas internacionales que lo vinculaban incurriría en responsabilidad internacional, con lo que admitieron una cierta relación en el derecho internacional y el derecho interno y una determinada primacía de aquél sobre éste. A su turno, los monistas admitieron que la potestad legislativa de los Estados no dependía de una delegación de competencias por parte del derecho internacional, aunque reafirmaban que en caso de conflicto entre ambas la norma internacional predominaba sobre la interna ${ }^{6}$.

La morigeración de la intensidad que aquellas posiciones extremas poseían altri tempi propició la aparición de concepciones más moderadas que entienden que la solución al problema teórico de las relaciones entre el derecho internacional y el derecho interno radica en la coordinación entre ambos sistemas jurídicos, cuyas relaciones no son sólo de conflicto sino de cooperación 7 . De allí que el derecho internacional no es irrelevante en el derecho interno, pero éste no desprende su validez y fuerza obligatoria de la delegación de competencias del derecho internacional. En tal sentido, el autor citado en último término concluye que "una norma interna contraria al derecho internacional es válida y obligatoria en el plano interno, aunque haga incurrir en responsabilidad internacional al Estado en cuestión por incumplimiento de una norma internacional que le vincule y obligue"s.

\section{La evolución de la jurisprudencia de la Corte Suprema argentina}

\section{Etapa anterior a la sentencia recaída en "Ekmekdjian c/ Sofovich"}

\section{A) Preludio}

Esta fase se revela proteica, sin una doctrina consistente y uniforme en torno a la vinculación del derecho internacional y el derecho interno, y a sus diversas facetas, por ejemplo: relación de los tratados internacionales y la Constitución y

\footnotetext{
${ }^{5}$ Pastor Ridruejo, José A., ibid., p. 169.

${ }^{6}$ Carrillo Salcedo, Juan A., Curso de Derecho Internacional Público. Introducción a su estructura, dinámica y funciones, $1^{\text {a }}$ ed., $2^{\text {a }}$ reimpres., Tecnos, Madrid, 1994, p. 149.

7 Ídem.

${ }^{8}$ Ídem.
} 
de aquéllos con las leyes internas; aplicación del derecho internacional consuetudinario; legitimidad del análisis de validez constitucional de las leyes aprobatorias de los tratados internacionales; operatividad de las normas de éstos; incorporación del derecho internacional convencional al ordenamiento jurídico interno, esto es, exigencia o no de un acto de transformación de aquél en derecho local; etc.

En general, durante este período la CSJN se decantó por una percepción dualista, matizada con algún dejo monista en el caso "Merck Química Argentina S.A. c/Gobierno de la Nación s/ Interdicto"' (9 de junio de 1948), aunque -como veremos- movida más por la necesidad de justificar determinadas decisiones políticas que por convicción jurídica. Por lo demás, de la compulsa de la línea jurisprudencial surgen otros ribetes e ingredientes dignos de mención.

\section{B) Algunos fallos}

a) Dentro de este apretado señalamiento, es preciso advertir liminarmente que, en principio, para la CSJN las cláusulas consagradas en los tratados internacionales no eran de aplicación inmediata (con algunas excepciones que veremos infra), sino que constituían normas programáticas.

Aunque no sigamos escrupulosamente una línea cronológica respecto de algunos pronunciamientos que enunciaremos más adelante, vemos por ejemplo que en "Alonso, Gregorio c/ Haras los Cardos"10 (15 de marzo de 1940), la Corte puntualizó que la Ley No 12.232 aprobatoria de las convenciones adoptadas por la Conferencia Internacional del Trabajo realizada en Ginebra en 1921, sólo importaba el compromiso de modificar la Ley de accidentes del trabajo 9.688.

b) Por su parte, en "Chantrain, Alfonso"11 (julio de 1947), mantuvo que los tratados internacionales deben respetar las disposiciones de la Constitución Nacional (C.N.), cuya supremacía sobre todas las normas de derecho positivo asegura el art. 31 de la misma; y en "Becker, Juan Sigfrido y otros"12 (27 de junio de 1947), señaló que "los tratados internacionales son parte de la ley suprema siempre que no estén en contradicción con ella” ${ }^{13}$.

\footnotetext{
${ }^{9}$ Fallos, 211:161. Resuelto por mayoría, compuesta por los doctores Pérez, Longhi, Álvarez Rodríguez y Valenzuela. Disidentemente, se pronunció el ministro Casares.

${ }^{10}$ Fallos, 186:258.

${ }^{11}$ Fallos, 208:84.

${ }^{12}$ Fallos, 208:39.

${ }^{13}$ Voto disidente del doctor González Calderón (Fallos, 208:41).

Éste señaló que "los tratados internacionales no pueden conceptuarse como parte de la Ley Suprema sino en tanto y en cuanto son concertados en consecuencia de ella (Constitución, art. 31), vale decir, siempre que no estén en contradicción con la misma".
} 
En síntesis, dicho art. 31 de la C.N. se interpretaba en el sentido de la preeminencia del derecho nacional sobre el internacional, dado que la cláusula fijaba (en la conclusión emergente de tal hermenéutica) el siguiente orden prelativo: Constitución, leyes y tratados internacionales.

c) A su tiempo, en la citada causa "Merck Química" y para legitimar la incautación por el Estado argentino de los bienes de tal empresa alemana, considerados propiedad enemiga (pues aquél había declarado la guerra a Alemania prácticamente sobre el fin de la segunda gran conflagración mundial), diseñó una suerte de doble estándar indicando que en tiempos de paz se mantiene en el orden interno la supremacía de la Constitución sobre los tratados internacionales (arts. 31 y 27 de la C.N.), y que "en tanto se trate de mantener la paz o afianzar el comercio con las potencias extranjeras, la República se conduce dentro de las orientaciones de la teoría 'dualista” (énfasis agregado).

Pero, "en el caso de una guerra por causa propia -eventualidad no incluida y extraña, por lo tanto, a la regla del art. 27 de la Constitución-, se aparta de esos principios y coloca al pais y a su gobierno en el trance de cumplir los tratados con todo rigorismo de que están animados ..." (bastardilla añadida), apreciación que destilaba un cierto rasgo monista.

d) En los casos "Martín y Cía. Ltda. S.A. c/ Administración General de Puertos s/ Repetición de pago"14 (6 de noviembre de 1963) y "Esso S.A. Petrolera Argentina c/ Nación Argentina" ${ }^{15}$ (5 de junio de 1968), la Corte igualó jerárquicamente a la ley y al tratado internacional, fundándose en la doctrina y la jurisprudencia norteamericanas.

Sobre el particular, el criterio sostenido puede sintetizarse así: No existe fundamento normativo para acordar prioridad de rango o superioridad a los tratados con las potencias extranjeras respecto de las leyes válidamente dictadas por el Congreso de la Nación. Y respecto de ambos rige el principio de que las normas posteriores derogan

\footnotetext{
${ }^{14}$ Fallos, 257:99. Votaron coincidentemente los doctores Villegas Basavilbaso, Aráoz de Lamadrid, Aberastury, Imaz y Bidau.

En esa ocasión se había llevado a conocimiento de la Corte Suprema la cuestión acerca de si el Decreto Ley No 6.575/58 (Ley No 14.467) modificaba el Tratado de Comercio y Navegación suscripto con la República de Brasil en 1940 (aprobado por Ley No 12.688), que establecía una exención de impuestos, tasas y gravámenes desconocida por el citado decreto ley.

${ }^{15}$ Fallos, 271:7. Suscribieron la sentencia los ministros Chute, Risolía, Cabral y Bidau.

En el caso se discutía si el Decreto No 5.153/55 (que establecía el pago de gravámenes para introducir vehículos importados al mercado interno) podía o no abrogar el Convenio Comercial entre Argentina y EE.UU. del 14 de octubre de 1941 (aprobado por Ley No 12.741 del 10 de julio de 1942). La CSJN, reiterando la doctrina sentada en Fallos, 257:99, consideró que aquel decreto era aplicable por ser contrario y posterior al mencionado convenio internacional.
} 
a las anteriores. Esa lectura de paridad jerárquica suponía que, en cualquier caso, el tratado internacional tendría siempre cotización infraconstitucional y en ocasiones podría ser inaplicado al quedar desplazado por la preferente valía de la ley interna, ya que en supuesto de conflicto entre ambos operaría la pauta de sucesión normativa, o sea, que la norma posterior deroga a la anterior; o eventualmente la de especialidad, en cuanto a que la norma especial se impone sobre la general.

Obviamente, y además de poner en serio riesgo la seguridad jurídica, semejante posición interpretativa colisionaba frontalmente contra la pauta pacta sunt servanda, principio general del derecho internacional operativo, incluso, fuera de todo vínculo convencional.

e) Otra imagen jurisprudencial asociada a una matriz dualista puede percibirse en "Cabrera, Washington Julio Efraín c/ Comisión Técnica Mixta de Salto Grande" 16 (5 de diciembre de 1983), donde mayoritariamente ${ }^{17}$ entendió que en caso de conflicto entre la Constitución y un convenio internacional (en el caso, el Acuerdo de Sede firmado el 15 de abril de 1977 entre aquella Comisión Técnica y la República Argentina) era posible declarar la inconstitucionalidad de la normativa aprobatoria del mismo, Ley 21.756, cuyo art. 4 establecía, a favor de la Comisión Técnica, "inmunidad contra todo procedimiento judicial o administrativo" y (en la argumentación del Procurador General -que la mayoría de la Corte siguió-) privaba al actor del derecho a la jurisdicción. Fue así como, frente al conflicto planteado entre la norma que por obra de un tratado acordaba inmunidad de jurisdicción a una de las partes, y la norma constitucional que reconocía a la otra el derecho a la jurisdicción, juzgó procedente la declaración de inconstitucionalidad de la primera de ellas sobre la base de opiniones doctrinarias y de la jurisprudencia de la propia Corte, sustentada en el art. 31 de la C.N. ${ }^{18}$

f) En relación con lo que advertíamos en punto a que, por principio, la CSJN se decantó por la programaticidad de las disposiciones de los convenios internacionales, cabe no obstante relevar algunos precedentes en los que confirió aplicabilidad operativa directa a ciertas disposiciones de aquéllos.

\footnotetext{
${ }^{16}$ Fallos, 305:2150.

${ }^{17}$ La posición mayoritaria correspondió a los doctores Rossi, Martínez Vivot y Gnecco, quienes participaron de los fundamentos del dictamen del Procurador General sobre la inconstitucionalidad de la norma cuestionada; añadiendo que la procedencia de una declaración en tal sentido se imponía al Tribunal por su función primordial de custodio de las garantías y principios consagrados en la C.N. y la jerarquía axiológica del derecho a la jurisdicción, afectado en la especie.

En voto concurrente conjunto se pronunciaron los ministros Gabrielli y Guastavino, quienes centraron fundamentalmente su argumentación en el "derecho de gentes".

${ }^{18}$ Una óptica iuscomparada en el campo de la fiscalización constitucional de los instrumentos internacionales puede verse en el libro de BAZÁN, Víctor, Jurisdicción constitucional y control de constitucionalidad de los tratados internacionales. Una visión de derecho comparado, Porrúa, México, D.F., 2003.
} 
Así lo hizo, v. gr., en: i) "Quebrachales Fusionados c/ Capitán, armadores y dueños del vapor nacional Águila s/ Indemnización de daños y perjuicios”'19 (9 de diciembre de 1927), en el que interpretó que la Convención sobre Abordaje, Asistencia y Salvamento marítimos firmada en Bruselas el 23 de septiembre de 1910, y aprobada por Ley 11.132, quedó de hecho incorporada y, por tanto, directamente integrada al Código de Comercio; ii) "Cía. Argentina de Navegación Nicolás Mihanovich Ltda. c/ Dueño y otros del vapor 'Duquesa" 20 (25 de junio de 1932), donde declaró improcedente el recurso extraordinario si la cuestión planteada fue resuelta por aplicación e interpretación de disposiciones del Código de Comercio y de cláusulas de la citada Convención de Bruselas de 1910, y iii) "S.A. Editorial Noguer" 21 (16 de mayo de 1962), ocasión en la que determinó - por mayoría- que el art. III de la Convención Universal sobre Derecho de Autor (del 6 de septiembre de 1952) debía aplicarse automáticamente, por cuanto ello resultaba del Decreto Ley No 12.088/57 (por medio del cual dicha Convención fue ratificada) y de lo estatuido en el art. 31 de la C.N., señalando además que, dentro de la esfera de su vigencia, el art. III, ap. $1^{\circ}$, de la Convención "modificó las disposiciones existentes en la Argentina respecto de la protección de la llamada "propiedad intelectual" 22 , refiriéndose a la Ley No 11.723.

g) Andando el tiempo, en los casos "Costa, Héctor R. c/ Municipalidad de la Ciudad de Buenos Aires y otros"23 (12 de marzo de 1987), "Sánchez Abelenda cl Ediciones de la Urraca"24 (1 de diciembre de 1988) y "Ekmekdjian c/ Neustadt" (1 de diciembre de 1988), la CSJN consideró que el derecho de réplica o rectificación consagrado en el art. 14.1 de la Convención Americana sobre Derechos

\footnotetext{
${ }^{19}$ Fallos, 150:84.

${ }^{20}$ Fallos, 165:144.

${ }^{21}$ Fallos, 252:262.

${ }^{22}$ Cfr. consids. $9^{\circ}$ y 11 de la mayoría.
}

Es interesante compulsar también el voto en disidencia de los ministros Boffi Boggero y Aberastury, quienes manifestaron: La Convención Universal de Ginebra sobre Derecho de Autor, de 1952, se halla incorporada al ordenamiento jurídico con el alcance de "ley suprema de la Nación", art. 31 de la C.N. Esa incorporación normativa surgía, no del Decreto No 1.155/58, que trataba de la licencia de traducción, sino de haber sido ratificado la convención por el Decreto Ley No $12.088 / 57$, sin que fuera necesaria al respecto, desde que ninguna salvedad o reserva se hizo, una ley especial de adaptación.

${ }^{23}$ Fallos, 310:508. Votaron mayoritariamente los doctores Belluscio, Petracchi y Bacqué; por su voto se pronunció el ministro Caballero, y en disidencia el doctor Fayt.

${ }^{24}$ Fallos, 311:2553. La mayoría quedó integrada por los doctores Belluscio y Bacqué. Concurrentemente, lo hizo el ministro Petracchi.

${ }^{25}$ Fallos, 311:2497. En mayoría se pronunciaron los ministros Petracchi y Bacqué y en voto concurrente el doctor Belluscio. 
Humanos $(\mathrm{CADH})$ aún no había sido objeto de reglamentación legal para ser tenido como derecho positivo interno. En otras palabras, consideraba que el compromiso asumido internacionalmente era programático. Ya específicamente en los dos últimos casos señaló, además, que tal derecho tampoco podía inferirse de la cláusula constitucional que -genéricamente- se refiere a los derechos implícitos (art. 33 C.N.), y que la operatividad que otorgara fuerza a aquel derecho no podría ser ejercida desde el Poder Judicial, porque se trataba de una cuestión de política legislativa ajena a la competencia de los órganos jurisdiccionales.

Naturalmente, la CSJN ignoraba así pautas básicas de la Convención de Viena sobre el Derecho de los Tratados ${ }^{26}$, obligatoria para nuestro país, que la aprobó por Ley No 19.865, ratificándola el Poder Ejecutivo Nacional el 5 de diciembre de 1972 y en vigor desde el 27 de enero de 1980, que acuerda primacía al derecho internacional convencional sobre el derecho interno y cuyo art. 27, bajo el rótulo de "El derecho interno y la observancia de los tratados" estipula: "Una parte no podrá invocar las disposiciones de su derecho interno como justificación del incumplimiento de un tratado..." -énfasis agregado-.

2. "EKMEKDJiAn C/ SOFOVICH" y OtROS FALlos POSTERIORES A ÉSTA, AUNQUE EN GENERAL ANTERIORES A LA REFORMA DE 1994

\section{A) "Ekmekdjian c/ Sofovich"}

En este paradigmático precedente, resuelto por mayoría $a^{27}$, la CSJN mudó radicalmente su jurisprudencia, se impregnó de una percepción monista y se anticipó a lo que, un par de años más tarde, la innovación constitucional de 1994 dispondría en cuanto a la valencia de los tratados internacionales en general, y a los relativos a derechos humanos en particular, vis-à-vis el derecho interno.

El Tribunal adjudicó aplicación directa y operativa al art. 14 de la CADH que contiene el derecho de rectificación o respuesta, aun cuando no existía una norma legal reglamentaria que lo desarrollase internamente ${ }^{28}$. Además, interpretó que la

\footnotetext{
${ }^{26}$ Del 23 de mayo de 1969 (U.N. Doc A/CONF.39/27 -1969-, 1155 U.N.T.S. 331).

${ }^{27}$ Se integró con los doctores Cavagna Martínez, Fayt, Barra, Nazareno y Boggiano; las disidencias correspondieron a los ministros Petracchi, Moliné O'Connor, Levene (h.) y Belluscio.

${ }^{28}$ Posteriormente, en "Petric Domagoj, Antonio c/ Diario Página 12", del 16 de abril de 1998 (Fallos, 321:885), la CSJN delineó algunos perfiles y alcances del derecho de rectificación o respuesta.

Ver sobre el particular, entre otros temas, BAZÁN, Víctor, "El derecho a la vida privada y el derecho a la libertad de información en la doctrina y jurisprudencia de la Corte Suprema de Justicia argentina", Estudios Constitucionales. Revista semestral del Centro de Estudios Constitucionales de Chile, Año 6, No 1, 2008, Universidad de Talca, Santiago de Chile, pp. 103-154.
} 
expresión "en las condiciones que establezca la ley" (art. 14.1, in fine, ibid.) se refiere "a los diversos sistemas jurídicos internos, integrados también por las sentencias de sus órganos jurisdiccionales, pues tanto la tarea judicial como legislativa persiguen el fin común de las soluciones valiosas" (consid. 22 de la mayoría).

Dicho en otros términos, puntualizó que el compromiso del orden jurídico interno con la $\mathrm{CADH}$ puede también ser cumplido por una sentencia judicial, estando habilitado el Tribunal para fijar "las características con que ese derecho, ya concedido por el tratado" será ejercitado en el caso concreto (consid. 22, in fine, de la mayoría).

La sentencia en cuestión dejó en claro que, en tanto la Convención estaba vigente para Argentina al momento en que dictaba el pronunciamiento (y, obviamente, también al tiempo en que el actor formuló su petición) y ostentaba jerarquía supralegal (hoy posee valencia constitucional), su incumplimiento -al influjo de la abstención legislativa- podría constituir omisión inconstitucional reparable judicialmente a través del amparo. En tal sentido, el fallo expresó: " $\mathrm{La}$ violación de un tratado internacional puede acaecer tanto por el establecimiento de normas internas que prescriban una conducta manifiestamente contraria, cuanto por la omisión de establecer disposiciones que hagan posible su cumplimiento. Ambas situaciones resultarian contradictorias con la previa ratificación internacional del tratado..." (remarcado añadido; consid. 16 del voto mayoritario). Por ende, la segunda de las hipótesis: "omisión de establecer disposiciones que hagan posible su cumplimiento", provocaría la agresión constitucional (y, en lenguaje más actual, también "convencional”) por inacción, y viabilizaría la fiscalización jurisdiccional a su respecto.

Es importante resaltar que el voto triunfante afirmó que:

- La Convención de Viena sobre el Derecho de los Tratados "confiere primacía al derecho internacional convencional sobre el derecho interno. Ahora esta prioridad de rango integra el ordenamiento jurídico argentino. La convención es un tratado internacional, constitucionalmente válido, que asigna prioridad a los tratados internacionales frente a la ley interna en el ámbito del derecho interno, esto es, un reconocimiento de la primacía del derecho internacional por el propio derecho interno" (énfasis añadido, consid. 18);

- "La necesaria aplicación del art. 27 de la Convención de Viena impone a los órganos del Estado argentino asignar primacía al tratado ante un eventual conflicto con cualquier norma interna contraria o con la omisión de dictar disposiciones que, en sus efectos, equivalgan al incumplimiento del tratado internacional en los términos del citado art. 27" (bastardilla añadida, consid. 19), y

- "la interpretación del Pacto debe, además, guiarse por la jurisprudencia de la Corte Interamericana de Derechos Humanos, uno de cuyos objetivos es la in- 
terpretación del Pacto de San José (Estatuto, art. 1º...” (consid. 21). Pasó luego a citar aprobatoriamente la Opinión Consultiva (O.C.) 7/86 $6^{29}$ (ver consids. 21 y ss.), en la que -entre otros aspectos- la Corte IDH interpretó el art. 14.1 del Pacto $^{30}$.

Además de sus reflejos anticipatorios respecto de la reforma constitucional de 1994, cuyos Convencionales de hecho nutrieron a la Ley Fundamental con algunos insumos conceptuales brindados en el fallo, la Corte proporcionó una solución de avanzada y sentó una laudable doctrina jurídica y axiológica en la materia, que situó a nuestro país a la vanguardia en Latinoamérica en lo relativo al nivel de avance jurisprudencial en torno al derecho internacional de los derechos humanos, su aplicación en el derecho interno y el seguimiento de los pronunciamientos de la Corte IDH (en casos contenciosos u opiniones consultivas).

\section{B) Algunos decisorios posteriores}

Sin intención alguna de taxatividad, pueden colacionarse los siguientes pronunciamientos:

a) El criterio trasuntado en "Ekmekdjian c/ Sofovich" aparece también esbozado en "Servini de Cubría, María R. s/ Amparo"31 (8 de septiembre de 1992), enfocando el art. 13 de la $\mathrm{CADH}$ (y la prohibición de previa censura). En este fallo se observan alusiones a precedentes consultivos de la Corte IDH en el consid. 25 del voto del

\footnotetext{
${ }^{29}$ O.C.-7/86, del 29 de agosto de 1986, "Exigibilidad del derecho de rectificación o respuesta (arts. 14.1, 1.1 y 2, CADH)", Serie A, No 7, San José de Costa Rica, 1986.

${ }^{30}$ La jurisprudencia de la Corte Interamericana alimentó, asimismo, la disidencia de los doctores Petracchi y Moliné O'Connor. Así, el consid. 14 refleja la cita de la O.C.-2/82 (del 24 de septiembre de 1982, "El efecto de las reservas sobre la entrada en vigencia de la CADH [arts. 74 y 75]", Serie A, No 2, San José de Costa Rica, 1982) y de la O.C.-1/82 (del 24 de septiembre de 1982, "'Otros tratados' objeto de la función consultiva de la Corte [art. 64, CADH]", Serie A, No 1, San José de Costa Rica, 1982); el consid. 16 se refiere a la O.C.-7/86 y la O.C.-2/82 y el consid. 17, nuevamente a la O.C.-7/86 (específicamente, la opinión separada del juez Gros Espiell).

Ya en el voto, también disidente, del doctor Levene (h.), en el consid. $9^{\circ}$-bien que implícitamente- se alude a la O.C.-2/82 y a la O.C.-3/83 (del 8 de septiembre de 1983, "Restricciones a la pena de muerte [arts. 4.2 y 4.4, CADH]", Serie A, No 3, San José de Costa Rica, 1983) y en el consid. 10, a la O.C.-7/86.

Para un estudio en general de las opiniones consultivas de la Corte IDH y de la O.C.-2/82 en particular, ver BAZÁN, Víctor, "La Convención Americana sobre Derechos Humanos y el efecto de las reservas respecto de su entrada en vigencia: a propósito de la O.C.-2/82 de la Corte Interamericana de Derechos Humanos", en Bidart Campos, Germán et al. (coords.), To I, Ediciones Jurídicas Cuyo, Mendoza, Argentina, 2000, pp. 91/165.

${ }^{31}$ Fallos, 315:1943. La mayoría se integró con los ministros Cavagna Martínez, Nazareno y Moliné O’Connor. Por medio de sendos votos concurrentes se pronunciaron los doctores Levene (h.), Fayt, Belluscio y Boggiano. Finalmente, en disidencias parciales individuales los ministros Barra y Petracchi.
} 
ministro Fayt, donde se alude a la O.C. $-5 / 85^{32}$; referencia reiterada en el voto del doctor Boggiano -consids. 15 a 17, donde también remite a la opinión separada del juez Gros Espiell-; en la disidencia parcial del ministro Barra -consids. 12 a 14, tramos donde figuran, asimismo, referencias a las opiniones separadas de los magistrados Piza Escalante y Gros Espiell-, y en la disidencia parcial del doctor Petracchi-consids. 25 y $26{ }^{33}$.

b) Es preciso advertir que, a los fines de evitar confusiones interpretativas que pusieran en jaque la supremacía de la Constitución (y su art. 27), la CSJN se sintió precisada a estrechar la primigenia laxitud de la afirmación que volcara en "Ekmekdjian c/ Sofovich" (primacía del derecho internacional sobre el derecho interno), al establecer en fallos posteriores que "el art. 27 de la Convención de Viena sobre el Derecho de los Tratados impone a los órganos del Estado argentino - una vez resguardados los principios de derecho público constitucionales ${ }^{34}$ - asegurar la primacía a los tratados ante un conflicto con una norma interna contraria, pues esa prioridad de rango integra el orden jurídico argentino y es invocable con sustento en el art. 31 de la Carta Magna" -destacado nuestro-.

Ello así en "Cafés La Virginia S.A. s/ Apelación - por denegación de repetición-" 35 (13 de octubre de 1994), consid. 90 de la mayoría, y su remisión a "Fibraca Constructora S.C.A. c/ Comisión Técnica Mixta de Salto Grande"36 (7 de julio de 1993), consid. $3^{\circ}$.

Este último pronunciamiento, al establecer la supremacía de los tratados internacionales sobre las leyes internas (conclusión que juzgó más acorde con las exigencias de cooperación, armonización e integración internacionales que la República Argentina había hecho propias, y que eliminaba la eventual responsabilidad del Estado por los actos de sus órganos internos), modificó la cuestionable doctrina sostenida en los citados casos "Martín c/ Administración General de Puertos" y

${ }^{32}$ O.C.-5/85, 13 de noviembre de 1985, "La colegiación obligatoria de periodistas (arts. 13 y 29, CADH)", Serie A, No 5, San José de Costa Rica, 1985.

${ }^{33}$ Entre otros fallos, puede mencionarse que en “Artigue, Sergio P.", del 25 de marzo de 1994 (Fallos, 317:247), específicamente en el consid. 14 del voto del doctor Petracchi se cita la mencionada O.C.-7/86 -opinión separada del juez Piza Escalante-.

${ }^{34}$ Se corporiza allí una clara referencia al art. 27 de la C.N.

${ }^{35}$ Fallos, 317:1282. La mayoría se conformó con los doctores Levene (h.), Belluscio, Nazareno, López y Bossert; por su voto se expidió el ministro Boggiano y en disidencia lo hizo el doctor Moliné O'Connor.

Vale aclarar que si bien la fecha del fallo es posterior a la reforma constitucional de 1994, en él no se hizo referencia a dicha innovación de la Ley Fundamental, resolviéndose de conformidad con la normativa anterior a la misma.

${ }^{36}$ Fallos, 316:1669. Votaron coincidentemente los ministros Barra, Belluscio, Levene (h.), Cavagna Martínez, Nazareno y Moliné O'Connor. 
"Esso c/ Nación Argentina", además de declarar inaplicable al caso el mencionado precedente "Cabrera c/ Comisión Técnica Mixta de Salto Grande".

c) Si bien no directamente relacionado con la materia de derechos humanos, en "Cocchia, Jorge Daniel c/ Estado Nacional y otro s/ Acción de amparo"37 (2 de diciembre de 1993), en lo que aquí interesa, la mayoría de la Corte sostuvo (anticipándose de alguna manera al espíritu inoculado a la regla del art. 75, inc. 24, de la C.N.): "El Tratado de Asunción de 1991 ratificado por la Ley No 23.981, que establece el Mercosur, constituye la culminación de un proceso de toma común de conciencia entre las naciones de la región, y es una clara definición de política legislativa que el ordenamiento jurídico interno no puede contradecir, dificultar $u$ omitir en su implementación práctica"38 (énfasis agregado).

\section{LA MODIFICACIÓN CONSTITUCIONAL DE 1994, SU IMPACTO EN MATERIA DE} DERECHOS HUMANOS Y ALGUNAS SENTENCIAS IMPREGNADAS DE LOS PRINCIPIOS Y

VALORES IUSFUNDAMENTALES DE LA REFORMA

\section{A) Reacondicionamiento del escenario constitucional}

Es innegable la fuerte incidencia que, al menos desde el plano normativo, ha originado la reforma constitucional de 1994 en el campo de los derechos humanos.

Pueden contabilizarse en tal sentido, sólo enunciativamente: la ampliación del plafón de derechos explícitos (v. gr., arts. 37, 41, 42 de la C.N.); la literalización de los procesos constitucionales de amparo, hábeas corpus y hábeas data (art. 43, ibid.); el diseño de un nuevo paradigma del principio de igualdad, caracterizado por la exigencia de complementación de la igualdad formal (art. 16, ibid.) con la igualdad material (artículos constitucionales 37 y 75, incs. 2º 19 y 23), y la adjudicación de jerarquía constitucional a once instrumentos internacionales en materia de derechos humanos (art. 75, inc. 22, párr. $2^{\circ}$, ibíd.), que hacen que la antigua figura de la 'pirámide' en la que su vértice superior era ocupado en solitario por la Constitución, haya devenido en una especie de 'trapecio' en cuyo plano más elevado comparten espacios en constante retroalimentación la Ley Fundamental y los documentos internacionales sobre derechos humanos con idéntica valía.

El elemento citado en último término (adjudicación de rango constitucional a los instrumentos internacionales sobre la materia mencionada) ha producido

${ }^{37}$ Fallos, 316:2624.

${ }^{38}$ La mayoría estuvo compuesta por los doctores Barra, Cavagna Martínez, Nazareno y Moliné O'Connor. En disidencia se pronunciaron los ministros Fayt, Belluscio y Petracchi. 
diversos efectos, entre los cuales pueden citarse ejemplificativamente: la amplificación cuantitativa y cualitativa del elenco de derechos implícitos y explícitos; la instauración de los principios pro homine o favor libertatis y pro actione, con los criterios hermenéuticos que vienen por añadidura: interpretación de buena fe, pacta sunt servanda y los atinentes al objeto y el fin de los tratados; la vigorización de la pauta que determina la imposibilidad de alegar la existencia o inexistencia de normas de derecho interno para dejar de cumplir compromisos internacionales, y la ineludible responsabilidad internacional en caso de incumplimiento de éstos.

Correlativamente a la citada adjudicación de jerarquía constitucional a un generoso conjunto de instrumentos internacionales sobre derechos humanos por la Convención Constituyente de 1994 o posteriormente por el Congreso de la Nación ${ }^{39}$ mediante la facultad contenida en el párrafo final del art. 75, inc. 22, la nombrada reforma constitucional también ha generado, entre otros puntos, la necesidad de asegurar el remozado principio de igualdad a través de acciones positivas y la inexcusable implicación de todas las autoridades públicas en tales tareas, en un escenario donde es imposible perder de vista el torrente axiológico que proporciona el imperativo preambular de "afianzar la justicia".

Todo ello fortalece la exigibilidad y la justiciabilidad de los derechos y compele al Estado argentino a volcar todos los esfuerzos y recursos posibles en el cabal cumplimiento de las exigencias internacionales asumidas en tal ámbito. Obviamente, ello presupone la existencia de una justicia constitucional -con la CSJN como órgano de cierre- activa, comprometida, prudente y responsable.

\section{B) El nivel de acatamiento por la CSJN de las sentencias y opiniones consultivas de la Corte IDH y los informes de la Comisión Interamericana de Derechos Humanos (Comisión IDH)}

a) Es importante destacar que en "Giroldi, Horacio D. y otro s/ Recurso de casación" ${ }^{40}$ (7 de abril de 1995), la CSJN sostuvo que la expresión "en las condiciones de su vigencia”, bajo la que adquiere jerarquía constitucional la $\mathrm{CADH}$ (art. 75, inc. 22, párr. 20), significa el modo como ella "efectivamente rige en el

\footnotetext{
${ }^{39} \mathrm{~A}$ la nómina primigenia de instrumentos internacionales con jerarquía constitucional originaria contenida en el art. 75, inc. 22, párr. $2^{\circ}$, de la Ley Fundamental, se han añadido, con idéntica alcurnia (aunque derivada), la Convención Interamericana sobre Desaparición Forzada de Personas (a la que se ha deparado tal calidad por medio de la Ley No 24.820, publicada el 29 de mayo de 1997) y la Convención sobre la Imprescriptibilidad de los Crímenes de Guerra y de los Crímenes de Lesa Humanidad (a la que se le ha conferido esa valía mediante la Ley No 25.778, publicada el 3 de septiembre de 2003).

${ }^{40}$ Fallos, 318:514. Votaron coincidentemente los ministros Nazareno, Moliné O'Connor, Fayt, Belluscio, Petracchi y Boggiano.
} 
ámbito internacional y considerando particularmente su efectiva aplicación jurisprudencial por los tribunales internacionales competentes para su interpretación y aplicación" (consid. 11, párr. 1º), de ahí que "la aludida jurisprudencia deba servir de guía para la interpretación de los preceptos convencionales en la medida en que el Estado argentino reconoció la competencia de la Corte Interamericana para conocer en todos los casos relativos a la interpretación y aplicación de la Convención Americana" (arts. 75, de la C.N., 62 y 64 de la CADH, y 2 de la Ley No 23.054 ${ }^{41}$ ) -consid. 11, párr. $2^{\circ}-$.

No puede ocultarse, sin embargo, que si bien aquella posición jurisprudencial ha sido mantenida en líneas generales por la Corte Suprema, no ha dejado de sufrir algunos avatares, por ejemplo, en el caso "Procurador del Tesoro de la Nación (en Autos 'Cantos, José M., expediente 1.307/2003')”² (21 de agosto de 2003), en el cual desestimó por mayoría una presentación del Procurador General del Tesoro que pretendía que el Tribunal diera cumplimiento a una sentencia de la Corte IDH que había declarado que el Estado argentino violó normas de la CADH y que debía abstenerse de perseguir el cobro de la tasa de justicia y de una multa impuesta, reducir razonablemente los honorarios regulados y asumir el pago de costas en una causa donde fue parte. El Tribunal declinó la intervención requerida, aduciendo que un temperamento contrario importaría infringir cláusulas de raigambre constitucional cuya titularidad correspondía a diversos profesionales que actuaron en la causa "C.1099.XX, 'Cantos, José María c/ Santiago del Estero, Provincia de y/o Estado Nacional s/ Cobro de pesos', con patente y deliberada renuncia de su más alta y trascendente atribución, para cuyo ejercicio había sido instituida como titular del Poder Judicial de la Nación, que es ser el custodio e intérprete final de la C.N. (consid. $3^{\circ}$ de la mayoría). Además, y entre otros argumentos, sostuvo que, "bajo el ropaje de dar cumplimiento con una obligación emanada de un tratado con jerarquía constitucional (art. 63.1, de la Convención), llevaría a la inicua -cuanto paradójica- situación, de hacer incurrir al Estado argentino en responsabilidad internacional por afectar garantías y derechos reconocidos a los profesionales, precisamente, en el instrumento cuyo acatamiento se invoca" (consid. $4^{\mathrm{o}}$ del voto mayoritario).

\footnotetext{
${ }^{41}$ Mediante la Ley No 23.054, la República Argentina aprobó la CADH. Específicamente el art. 2 de dicha ley plasma el reconocimiento argentino de la competencia de la Comisión y la Corte Interamericanas.

${ }^{42}$ Fallos, 326:2968.

La mayoría estuvo compuesta por los doctores Fayt y Moliné O’Connor; por su voto, lo hicieron los doctores Petracchi y López (de modo conjunto) y Vázquez (individualmente); por último, los doctores Boggiano y Maqueda plantearon sendas disidencias, siendo relevante remarcar que este último mocionó el cumplimiento directo del pronunciamiento de la Corte Interamericana.
} 
Más adelante, en "Espósito, Miguel Ángel s/ Incidente de prescripción de la acción penal promovido por su defensa" (23 de diciembre de 2004), la Corte Suprema retomó -al menos por parte de varios de sus componentes- un discurso demostrativo de su permeabilidad a acatar los pronunciamientos del Tribunal con sede en Costa Rica, al admitir mayoritariamente ${ }^{43}$ el recurso extraordinario deducido contra una sentencia que había declarado extinta la acción penal por prescripción en una causa abierta por hechos que luego fueron juzgados por dicha Corte Interamericana, cuyas decisiones -sostuvo la Corte Suprema- resultan de "cumplimiento obligatorio para el Estado argentino (art. 68.1, CADH)", por lo cual también ella, en principio, debía subordinar el contenido de sus decisiones a las de dicho Tribunal internacional (consid. $6^{\circ}$ de la mayoría). Previamente, había puntualizado que el rechazo de la apelación tendría como efecto inmediato la confirmación de la declaración de prescripción de la acción penal, en contravención a lo decidido por la Corte Interamericana en su sentencia del 18 de septiembre de 2003 en el caso "Bulacio vs. Argentina" ${ }^{44}$, en el que se declarara la responsabilidad internacional del país -entre otros puntos- por la deficiente tramitación del expediente en cuestión (consid. $5^{\circ}$ del voto triunfante).

No puede obviarse, por último, lo resuelto en "Mazzeo, Julio Lilo y otros s/ Recurso de casación e inconstitucionalidad" 45 (13 de julio de 2007), donde por mayoría ${ }^{46}$ se refirió al control de convencionalidad que deben llevar adelante los jueces locales respecto de la normativa local que apliquen, tomando en consideración para ello no sólo el articulado de la $\mathrm{CADH}$ sino también el modo como esta es interpretada por la Corte IDH (volveremos sobre el particular).

b) De su lado, la trayectoria jurisprudencial de la CSJN ha sido un tanto vacilante respecto de la cotización de los informes y recomendaciones de la Comisión IDH.

Así, mimetizándose con "Giroldi”, en "Bramajo, Hernán, J.” (12 de septiembre de 1996) le asignó la calidad de "guía para la interpretación de los preceptos convencionales a la opinión de la Comisión Interamericana”, en la medida en que el Estado argentino reconoció la competencia de ésta para conocer en todos

\footnotetext{
${ }^{43}$ Fallos, 327:5668.

Formaron la mayoría los doctores Petracchi y Zaffaroni; por su voto, lo hicieron los doctores Belluscio y Maqueda (conjuntamente), y Fayt, Boggiano y Highton de Nolasco, de modo individual.

${ }^{44}$ Corte IDH, "Caso Bulacio vs. Argentina”, Sentencia de Fondo, Reparaciones y Costas, 18 de septiembre de 2003, Serie C, No 100.

${ }^{45}$ Fallos, 330:3248.

${ }^{46}$ Los alineamientos fueron: por la mayoría, los doctores Lorenzetti, Highton de Nolasco, Maqueda y Zaffaroni; en disidencia se expidió el ministro Fayt y en disidencia parcial lo hizo la doctora Argibay.
} 
los casos relativos a la interpretación y la aplicación de la CADH (consid. $8^{\circ} \mathrm{del}$ voto de la mayoría $)^{47}$, aunque luego plasmó un repliegue de la amplia posición primigenia, cuando en la causa "Acosta, Claudia B.” (22 de diciembre de 1998), aclaró que, si bien por el principio de buena fe que rige la actuación del Estado argentino en el cumplimiento de sus compromisos internacionales, éste "debe realizar los mejores esfuerzos para dar respuesta favorable a las recomendaciones efectuadas por la Comisión, ello no equivale a consagrar como deber para los jueces el de dar cumplimiento a su contenido, al no tratarse aquéllas de decisiones vinculantes para el Poder Judicial" (consid. 13 de la mayoría) ${ }^{48}$.

La variación de criterio es fácilmente verificable. Basta con constatar que en idéntica fecha en que decidió el caso "Acosta”, esto es, el 22 de diciembre de 1998, pronunció sentencia en "Nápoli, Erika Elizabeth y otros s/ Infracción art. 139 bis del Código Penal" ${ }^{49}$, en cuyo consid. 18 de la mayoría ${ }^{50}$ reiteró lo manifestado en "Giroldi" -incluso remitió a tal pronunciamiento (concretamente al $2^{\circ}$ párr. del consid. 11) - respecto a que la jurisprudencia de la Corte IDH debe servir de guía para la interpretación de la $\mathrm{CADH}$.

Ello deja en claro la intención de seccionar los criterios que a partir de entonces asumía, manteniendo su posición en torno a la imperatividad de los decisorios de la Corte IDH, refrendada en "Nápoli", y paralelamente decantándose por la no vinculatoriedad de los pronunciamientos de la Comisión IDH, que el mismo día comenzó a perfilar en "Acosta".

La visión jurídica inoculada a "Acosta" fue confirmada en "Felicetti, Roberto y otros" (21 de diciembre de 2000), causa vinculada con el copamiento de La Tablada (ver consid. $6^{0}$ de la mayoría) $)^{51}$, y -ya tangencialmente- en "Alonso,

${ }^{47}$ Fallos, 319:1840.

La posición que se impuso quedó integrada con los doctores Nazareno, Moliné O'Connor, Boggiano, López y Vázquez. En disidencia conjunta votaron los ministros Fayt, Belluscio y Bossert.

${ }^{48}$ Fallos, 321:3555.

La posición mayoritaria estuvo compuesta por los ministros Nazareno, Moliné O’Connor, Fayt, Belluscio, López y Vázquez. Por su voto se expidieron, conjunta y concurrentemente, los doctores Bossert y Boggiano. Por su parte, el ministro Petracchi lo hizo en disidencia.

${ }^{49}$ Fallos, 321:3630.

${ }^{50} \mathrm{El}$ voto mayoritario fue rubricado por los doctores Belluscio, Boggiano, López y Vázquez. Por su voto, lo hizo el ministro Fayt. Finalmente, los doctores Petracchi y Bossert se expidieron en sendas disidencias.

${ }^{51}$ Fallos, 323:4130.

El sentido de los votos emitidos fue el siguiente: por la mayoría, se expidieron los doctores Nazareno, Moliné O’Connor, Belluscio, López y Vázquez; además, hubo sendas disidencias de parte de los ministros Fayt, Petracchi, Boggiano y Bossert. 
Jorge F. s/ Recurso de casación”, del 19 de septiembre de 2002 (consid. 5 del voto mayoritario $)^{52}$.

No obstante, en "Simón, Julio Héctor y otros s/ Privación ilegítima de la libertad, etc. -causa No 17.768-"53 (14 de junio de 2005), en el consid. 17 de la mayoría ${ }^{54}$ calificó a la jurisprudencia de la Corte Interamericana y a las directivas de la Comisión Interamericana como "una imprescindible pauta de interpretación de los deberes y obligaciones derivados de la Convención Americana sobre Derechos Humanos" (énfasis añadido), lo que refleja una revalorización de los pronunciamientos de la Comisión.

Resta aguardar que se afiance y luego evolucione cualitativamente la tendencia que la Corte retomara con mayores precisión terminológica y densidad jurídica en "Simón" vis-à-vis "Bramajo", internalizando definitivamente la vinculatoriedad jurídica de los informes de la Comisión IDH, sin perjuicio de su valor como premisas hermenéuticas.

C) El empleo de insumos argumentales sustentados en precedentes de diversos órganos internacionales cuasijurisdiccionales de protección de derechos humanos o en instrumentos de soft law

a) En "Campodónico de Beviacqua, Ana Carina c/ Ministerio de Salud y Acción Social - Secretaría de Programas de Salud y Banco de Drogas Neoplásicas” 55 (24 de octubre de 2000), por mayoría ${ }^{56}$, la Corte ratificó la sentencia de las instancias de mérito que habían hecho lugar al amparo articulado por la madre del niño A.S.B. (quien nació con un grave padecimiento en su médula ósea que reducía sus defensas inmunológicas y cuyo tratamiento dependía del suministro de un fármaco especial), condenando al Ministerio de Salud y Acción Social a entregar las dosis necesarias de la mencionada medicación, ya que el 2 de diciembre de 1998 el

\footnotetext{
${ }^{52}$ Fallos, 325:2322.

La mayoría estuvo compuesta por los ministros Nazareno, Moliné O’Connor, Belluscio, López y Vázquez; en disidencia lo hicieron los doctores Petracchi y Bossert (conjuntamente) y Boggiano (de manera individual).

${ }^{53}$ Fallos, 328:2056.

${ }^{54}$ El siguiente es el detalle de la votación: la moción que encabeza el fallo fue firmada por el doctor Petracchi. A su tiempo, en sendas concurrencias se pronunciaron los ministros Maqueda, Zaffaroni, Highton de Nolasco, Lorenzetti (los cuatro coinciden con los consids. 1 a 11 del voto del doctor Petracchi), Argibay (quien concuerda con los consids. 1 a 6 del mencionado voto del ministro Petracchi) y Boggiano. Finalmente, el doctor Fayt se expidió en disidencia.

${ }^{55}$ Fallos, 323:3229, 3239.

${ }^{56}$ Suscribieron coincidentemente el fallo los ministros Nazareno, Moliné O'Connor, Fayt, Petracchi, Boggiano, López y Vázquez. Sólo disintió el doctor Belluscio.
} 
Banco de Drogas Antineoplásicas -dependiente de aquél- manifestó a los padres de la criatura que les entregaba la medicación "por última vez", circunstancia que movió a éstos a articular la aludida acción.

Es de interés recalcar que, para dar forma a su razonamiento judicial, la mayoría de la Corte aludió al Comité de Derechos Económicos, Sociales y Culturales (Naciones Unidas), Observaciones finales al informe inicial de Suiza, en Informe sobre los periodos de sesiones $18^{\circ}$ y $19^{\circ}$ (22 de abril a 15 de mayo de 1998 y 16 de noviembre a 4 de diciembre de 1998), Naciones Unidas, Consejo Económico Social, Ginebra, 1999, No 2, pp. 66/68, párrs. 342, 347/349, 351 y 363/362.

b) En "Verbitsky, Horacio" 57 (3 de mayo de 2005), por mayoría ${ }^{58}$, diseñó un pronunciamiento novedoso (aunque de dificultoso cumplimiento), entre otros aspectos, porque -activismo mediante- dio vida a un remedio jurisdiccional para combatir las omisiones contrarias a la Constitución y a los instrumentos internacionales con valencia homóloga en que incurren las autoridades competentes en materia de ejecución penal en perjuicio de las personas privadas de su libertad en jurisdicción de la Provincia de Buenos Aires detenidas en establecimientos penales y comisarías sobrepoblados. Tales pretericiones resultaban violatorias, v.gr., del art. 18 de la C.N. y de los arts. XXV de la Declaración Americana de los Derechos y Deberes del Hombre, 10 del Pacto Internacional de Derechos Civiles y Políticos -PIDCP- y 5o, inc. $2^{\circ}$, de la CADH (ver consid. 39 de la mayoría).

Aunque en abstracto y a priori ostenten naturaleza y valor de soft law en materia de derecho internacional de los derechos humanos, el Tribunal elevó al nivel de estándar básico infranqueable a las "Reglas Minimas para el Tratamiento de Reclusos de las Naciones Unidas", recogidas por la Ley No 24.660, como elenco de pautas fundamentales a las que debe sujetarse toda detención para que la privación de la libertad ambulatoria legítimamente impuesta por un órgano judicial competente se adapte a los lineamientos indispensables para preservar la dignidad de la persona humana (cfr. íd. consid.).

Por lo demás, fue la primera vez que la Corte admitió un hábeas corpus correctivo colectivo en protección de los derechos fundamentales de personas privadas de su libertad, para intentar garantizarles -inter alia y como se anticipó- un encierro en condiciones carcelarias mínimas aceptables.

c) En la citada causa "Simón" afrontó el tema de la validez constitucional de las Leyes $\mathrm{No}^{\circ}$. 23.492, de "punto final”, y 23.521 de "obediencia debida”. Ambos

\footnotetext{
${ }^{57}$ Fallos, 328:1146.

${ }^{58}$ Conformada por los ministros Petracchi, Maqueda, Zaffaroni, Highton de Nolasco y Lorenzetti. Por su parte, en disidencia se expidió el doctor Boggiano y, también disidentemente -aunque sólo en forma parcial-, lo hicieron por separado los ministros Fayt y Argibay.
} 
dispositivos legales fueron abrogados por el art. $1^{\circ}$ de la Ley No 24.952 y, posteriormente, declarados insanablemente nulos por el art. $1^{\circ}$ de la Ley o 25.779 .

Concretamente, la mayoría del Tribunal declaró inconstitucionales las Leyes Nos. 23.492 y 23.521 y válida la Ley No 25.779. Al mismo tiempo, determinó a todo evento de ningún efecto, además de las dos leyes indicadas en primer término, a cualquier acto fundado en ellas que pudiera oponerse al avance de los procesos que se instruyeran, o al juzgamiento y eventual condena de los responsables, $\mathrm{u}$ obstaculizar en forma alguna las investigaciones llevadas a cabo por los canales procedentes y en el ámbito de sus respectivas competencias, por crímenes de lesa humanidad cometidos en el territorio de la Nación argentina.

Para forjar su razonamiento se sustentó en la decisión de la Corte IDH en el "Caso Barrios Altos vs. Perú"59, cuyas conclusiones -argumentó- debían ser imperativamente trasladadas al caso argentino, si es que las decisiones de tal Tribunal "han de ser interpretadas de buena fe como pautas jurisprudenciales" (consids. 23 y 24).

Además, puntualizó que quienes resultaron beneficiarios de las leyes de mención no podían invocar ni la prohibición de retroactividad de la ley penal más grave ni la cosa juzgada, pues de acuerdo con lo establecido por la Corte IDH, "tales principios no pueden convertirse en el impedimento para la anulación de las leyes mencionadas ni para la prosecución de las causas que fenecieron en razón de ellas, ni la de toda otra que hubiera debido iniciarse y no lo haya sido nunca. En otras palabras, la sujeción del Estado argentino a la jurisdicción interamericana impide que el principio de 'irretroactividad' de la ley penal sea invocado para incumplir los deberes asumidos en materia de persecución de violaciones graves a los derechos humanos" -remarcado agregado- (consid. 31).

Asimismo, remitió al Comité de Derechos Humanos de Naciones Unidas, órgano que había precisado que "cuando funcionarios públicos o agentes del Estado han cometido violaciones de los derechos del Pacto (...) los Estados Partes no pueden eximir a los autores de su responsabilidad personal como ha ocurrido con determinadas amnistías..." ${ }^{\circ 0}$. En el mismo sentido, la Corte añadió que las Observaciones Finales de dicho Comité sobre este tema dirigidas a la Argentina ${ }^{61}$ establecen la inadmisibilidad de la situación creada por las Leyes $\mathrm{N}^{\circ}$ s. 23.492 y

\footnotetext{
${ }^{59}$ Corte IDH, "Caso Barrios Altos, Chumbipuma Aguirre y otros vs. Perú", sentencia de 14 de marzo de 2001, Serie C, No 75, San José de Costa Rica.

${ }^{60}$ Observación General No 31, Comentarios generales adoptados por el Comité de Derechos Humanos, "La índole de la obligación jurídica general impuesta”, 80º período de sesiones (2004), párrs. 17 y ss.

${ }^{61}$ Sesión 1893, de $1^{\circ}$ de noviembre de 2000.
} 
23.521 también frente al PIDCP, así como la insuficiencia de la mera derogación de tales normas, expresando que: "Las violaciones graves de los derechos civiles y políticos durante el gobierno militar deben ser perseguibles durante todo el tiempo necesario y con toda la retroactividad necesaria para lograr el enjuiciamiento de sus autores" 62 (consid. 33).

d) En "Maldonado, Daniel Enrique y otro s/ Robo agravado por el uso de armas en concurso real con homicidio calificado -causa No $1174-"{ }^{63}$ (7 de diciembre de 2005), la Corte -por mayoría ${ }^{64}$ - dejó sin efecto la sentencia por la que se le había aplicado al imputado (menor, al momento del hecho delictual) la pena de prisión perpetua. Fundamentalmente, se basó en que:

- "El mandato constitucional que ordena que toda pena privativa de la libertad esté dirigida esencialmente a la reforma y readaptación social de los condenados (art. $5^{\circ}$, inc. 6, CADH) y que el tratamiento penitenciario se oriente a la reforma y readaptación social de los penados (art. 10, inc. $3^{\circ}$, PIDCP) exige que el sentenciante no se desentienda de los posibles efectos de la pena desde el punto de vista de la prevención especial. Dicho mandato, en el caso de los menores, es mucho más constrictivo y se traduce en el deber de fundamentar la necesidad de la privación de libertad impuesta, desde el punto de vista de las posibilidades de resocialización, lo cual supone ponderar cuidadosamente en ese juicio de necesidad los posibles efectos nocivos del encarcelamiento" (consid. 23);

- Los derechos especiales que tienen los menores por su condición, no constituyen sólo un postulado doctrinario, sino que su reconocimiento supone un imperativo jurídico de máxima jerarquía normativa, derivado de los tratados internacionales suscriptos por nuestro país, en especial de la Convención de los Derechos del Niño y la CADH. Aquella Convención establece los principios fundamentales para el sistema penal de menores en sus arts. 37 y 40 , mientras que el "Comité de los Derechos del Niño, intérprete de dicha Convención, ha recomendado a los Estados Parte asegurar la total implementación en la justicia penal juvenil a los estándares de la Convención Internacional del Niño en particular a los arts. 37, 39 y 40 de la Convención, así como a las Reglas Minimas de las Naciones Unidas para la Administración de la Justicia Juvenil (Reglas de Beijing) y a la Guia de las Naciones Unidas para la Prevención de la Delincuencia Juvenil (Reglas de RIAD) (Dominica CRC/C/15/Add.238.2004)"' (énfasis agregado, consid. 33), y

${ }^{62}$ Observación General No 31, cit., párr. 9.

${ }^{63}$ Fallos, 328:4343.

${ }^{64}$ La mayoría se integró con lo doctores Petracchi, Highton de Nolasco, Maqueda, Zaffaroni y Lorenzetti; mientras que por medio de respectivos votos concurrentes se pronunciaron los ministros Fayt y Argibay. 
- Que en la actualidad, el sistema jurídico de la justicia penal juvenil se encuentra configurado por la C.N., la Convención Internacional sobre los Derechos del Niño, la CADH, el PIDCP y el Pacto Internacional de Derechos Económicos, Sociales y Culturales, "normas que result[a]n de ineludible consideración al momento de la imposición de penas por hechos cometidos por menores" (consid. 34).

e) Unánimemente, en "Asociación Trabajadores del Estado c/ Ministerio de Trabajo" ${ }^{5}$ (11 de noviembre de 2008), la Corte declaró inconstitucional el art. 41, inc. 'a', de la Ley No 23.551 por violar el derecho a la libertad de asociación sindical amparado tanto por el art. 14 bis de la C.N. como por normas de pactos jerarquizados constitucionalmente conforme al art. 75, inc. 22, ibid., en la medida en que exige que los delegados del personal y los integrantes de las comisiones internas y organismos similares previstos en el art. 40 de la ley, deban estar afiliados a la respectiva asociación sindical con personería gremial y ser elegidos en comicios convocados por ésta (consid. $9^{\circ}$ ).

Convergentemente, señaló que los términos "libre y democrática" del art. 14 bis "dejan de ser recíprocamente complementarios" (consid. 70), agregando que este orden conceptual se corresponde con la interpretación del Convenio 87 de la Organización Internacional del Trabajo (OIT) y la labor de dos órganos de control internacional de la mencionada organización: el Comité de Libertad Sindical y la Comisión de Expertos en Aplicación de Convenios y Recomendaciones de la OIT (consid. 8o). Asimismo, se ha sustentado en el criterio del Comité de Derechos Económicos, Sociales y Culturales (que en repetidas oportunidades ha recomendado a los Estados adecuar su legislación al mencionado Convenio No 87 de la OIT) y en la posición de la Corte IDH, por ejemplo, en el "Caso Huilca Tecse"66.

\section{D) Crimenes de lesa humanidad. Control de convencionalidad}

a) En este primer segmento repasaremos sumariamente dos fallos: "Arancibia Clavel" y "Lariz Iriondo", que han generado opiniones discordantes acerca de si las respectivas decisiones que vehiculan resultan o no coherentes entre sí.

i) En "Arancibia Clavel, Enrique Lautaro s/ Homicidio calificado y asociación ilícita y otros -causa No 259-"67 (24 de agosto de 2004), afrontó el controvertido asunto de la prescripción de la acción penal establecida en el ordenamiento jurí-

\footnotetext{
${ }^{65}$ Fallos, 331:2499. Firmaron los doctores Lorenzetti, Highton de Nolasco, Fayt, Petracchi, Maqueda y Zaffaroni.

${ }^{66}$ Corte IDH, "Caso Huilca Tecse vs. Perú", Sentencia de Fondo, Reparaciones y Costas, 3 de marzo de 2005, Serie C, No 121, párrs. 69, 70, 72, 74 y 75.

${ }^{67}$ Fallos, 327:3294.
} 
dico interno vis-à-vis el derecho internacional consuetudinario y convencional, en el ámbito de los crímenes o delitos de lesa humanidad ${ }^{68}$. Concretamente, la mayoría ${ }^{69}$ juzgó:

- Que los delitos como el genocidio, la tortura, la desaparición forzada de personas, el homicidio y cualquier otro tipo de actos dirigidos a perseguir y exterminar opositores políticos, pueden ser considerados crimenes contra la humanidad, porque atentan contra el derecho de gentes tal como lo prescribe el art. 118 de la C.N. (consid. 16); y que, en consecuencia, el formar parte de un grupo dedicado a perpetrar estos hechos, independientemente del rol funcional que se ocupe, también es un crimen contra la humanidad (consid. 17);

- Que a partir del fallo de la Corte IDH en el "Caso Velásquez Rodríguez vs. Honduras"70, "quedó claramente establecido el deber del Estado de estructurar el aparato gubernamental, en todas sus estructuras del ejercicio del poder público, de tal manera que sus instituciones sean capaces de asegurar la vigencia de los derechos humanos, lo cual incluye el deber de prevenir, investigar y sancionar toda violación de los derechos reconocidos por la convención. Desde este punto de vista, la aplicación de las disposiciones de derecho interno sobre prescripción constituye una violación del deber del Estado de perseguir y sancionar, y consecuentemente, compromete su responsabilidad internacional (conf. CIDH, caso 'Barrios Altos', sentencia del 14 de marzo de 2001, considerando 41, Serie C No 75; caso 'Trujillo Oroza vs. Bolivia', Reparaciones, sentencia del 27 de febrero de 2002, considerando 106, Serie C No 92; caso 'Benavides Cevallos', Cumplimiento de sentencia, resolución del 9 de septiembre de 2003, considerandos 6 y 7)" -énfasis añadido- (consid. 36, párr. 2\%), y

- Que a pesar de haber transcurrido el plazo previsto por el art. 62, inc. $2^{\circ}$, en función del art. 210 del Código Penal, corresponde declarar que la acción penal no se había extinguido respecto de Enrique Lautaro Arancibia Clavel, por cuanto las reglas de prescripción de la acción penal previstas en el ordenamiento jurídico interno quedan desplazadas por el derecho internacional consuetudinario y por la Convención sobre la Imprescriptibilidad de los Crimenes de Guerra y de los Crimenes de Lesa Humanidad (consid. 38).

\footnotetext{
${ }^{68}$ El criterio sentado en "Arancibia Clavel" fue luego reiterado en la causa E.191.XLIII, "Etchecolatz, Miguel Osvaldo s/ recurso extraordinario", de 17 de febrero de 2009.

${ }^{69}$ Los votos respondieron al siguiente detalle: los doctores Zaffaroni y Highton de Nolasco suscribieron la posición mayoritaria. A su tiempo, los ministros Petracchi, Boggiano y Maqueda firmaron sendas concurrencias. Finalmente, por medio de disidencias individuales se pronunciaron los doctores Belluscio, Fayt y Vázquez.

${ }^{70}$ Corte IDH, "Caso Velásquez Rodríguez vs. Honduras”, Sentencia de Fondo, 29 de julio de 1988, Serie C, No 4, párr. 172.
} 
ii) Por su parte, en "Lariz Iriondo, Jesús M."71 (10 de mayo de 2005) el Tribunal desestimó el recurso ordinario de apelación interpuesto por el Ministerio Público Fiscal y confirmó la sentencia de primera instancia que había desestimado el pedido de extradición realizado por España respecto de un miembro de la organización terrorista ETA en virtud de la colocación y detonación de explosivos en la vía pública.

Del consid. 26 del voto que encabeza el decisorio ${ }^{72}$ surge que la Corte "considera que en el derecho internacional no existe un desarrollo progresivo suficiente que permita concluir que todos y cada uno de los actos que a partir de tratados internacionales pasan a ser calificados como 'actos de terrorismo' puedan reputarse, tan sólo por esa circunstancia delitos de lesa humanidad”.

iii) Colocados ambos fallos en perspectiva, GeLlı opina que la Corte diseña una línea que divide diferentes tipos de terrorismo, algunos de los cuales -por ejemplo, cuando se trata de actos cometidos por personas asociadas ilícitamente para ello- no son delitos políticos pero tampoco de lesa humanidad ${ }^{73}$, concluyendo que la cuestión jurídica luce problemática en nuestro país, "y en algún punto contradictoria con las soluciones concretas que se han articulado", por lo que, para enderezarla, se "requiere, en primer término, sincerar los parámetros de política institucional que deben resolverla"74.

b) En el nombrado caso "Mazzeo", la CSJN aportó un relevante enfoque institucional en torno a la invalidez constitucional de la atribución presidencial de emitir indultos que beneficien a sujetos acusados de cometer delitos de lesa humanidad (ver, por ejemplo, el consid. 31 de la moción triunfante).

Para conformar tal esquema argumental, donde resalta el consid. 21 de la posición mayoritaria en punto al deber del poder judicial local de realizar el control de convencionalidad, esto es, discernir si una norma interna es o no "convencional", se hizo eco de la pauta plasmada por la Corte IDH en el párr. 124 de la sentencia recaída en el "Caso Almonacid Arellano vs. Chile”, en el que se pronunció en los siguientes términos: "La Corte es consciente que los jueces y tribunales internos están sujetos al imperio de la ley y, por ello, están obligados a aplicar las disposi-

\footnotetext{
${ }^{71}$ Fallos, 328:1268.

${ }^{72}$ El voto triunfante fue firmado por los doctores Petracchi, Highton de Nolasco, Lorenzetti y Argibay. Por su voto, se expidieron los ministros Maqueda y Zaffaroni, conjuntamente; y Belluscio y Fayt, de manera individual. A su tiempo, la solitaria disidencia fue del doctor Boggiano.

${ }^{73}$ Cfr. GelLi, María Angélica, "El terrorismo y el desarrollo progresivo de un delito internacional", La Ley, Buenos Aires, To 2005-E, pp. 1179/1180.

${ }^{74}$ Ibíd., p. 1180.
} 
ciones vigentes en el ordenamiento jurídico. Pero cuando un Estado ha ratificado un tratado internacional como la Convención Americana, sus jueces, como parte del aparato del Estado, también están sometidos a ella, lo que les obliga a velar porque los efectos de las disposiciones de la Convención no se vean mermados por la aplicación de leyes contrarias a su objeto y fin, y que desde un inicio carecen de efectos jurídicos. En otras palabras, el Poder Judicial debe ejercer una especie de 'control de convencionalidad' entre las normas jurídicas internas que aplican en los casos concretos y la Convención Americana sobre Derechos Humanos. En esta tarea, el Poder Judicial debe tener en cuenta no solamente el tratado, sino también la interpretación que del mismo ha hecho la Corte Interamericana, intérprete última de la Convención Americana" (remarcado añadido) ${ }^{75}$.

Para dejar paso al epílogo de este trabajo, sólo mencionaremos que, al modo como el Tribunal interamericano destacó en el "Caso Boyce y otros vs. Barbados", lo señalado en el párrafo anterior significa que no alcanza con limitarse a evaluar si una norma es inconstitucional, sino que la cuestión debe girar en torno a si la misma también es "convencional", o sea, debe además el órgano jurisdiccional en cuestión decidir si ella restringe o viola los derechos reconocidos en la $\mathrm{CADH}^{76}$.

\section{CONSIDERACIONES FINALES}

1. Es indisimulable el fuerte impacto que la reforma constitucional de 1994 ha provocado en el ámbito de los derechos humanos en el escenario jurídico argentino.

Esa huella puede verificarse tomando en cuenta, por ejemplo: la adjudicación de jerarquía constitucional a un nutrido conjunto de instrumentos internacionales sobre la materia y los recipiendarios ex post de tal valía; la reafirmación de los principios pro homine o favor libertatis y pro actione; la prefiguración de una dimensión sustancial, complementaria de la formal, en torno al principio de igualdad, exigiéndosele al Estado que busque simetrías a través de "acciones positivas"; la literalización en la Constitución de los procesos constitucionales de amparo, hábeas corpus y hábeas data para resguardar derechos fundamentales, y la incorporación al texto constitucional de derechos que hasta la citada innovación no estaban literalmente explicitados.

\footnotetext{
${ }^{75}$ Corte IDH, "Caso Almonacid Arellano y otros vs. Chile", Sentencia sobre Excepciones Preliminares, Fondo, Reparaciones y Costas, 26 de septiembre de 2006, Serie C, No 154.

También lo ha expresado, v.gr., en el "Caso La Cantuta vs. Perú", Sentencia sobre Fondo, Reparaciones y Costas, 29 de noviembre de 2006, Serie C, No 162, párr. 173.

${ }^{76}$ Corte IDH, "Caso Boyce y otros vs. Barbados", Sentencia sobre Excepción Preliminar, Fondo, Reparaciones y Costas, 20 de noviembre de 2007, Serie C, No 169, párr. 78.
} 
Todo ello da cuerpo a un compacto de factores envueltos y recorridos por el caudal axiológico que les suministra el imperativo preambular de "afianzar la justicia”, que compromete al Estado argentino más allá de las palabras y lo compele a volcar todos los esfuerzos y recursos posibles en el cabal cumplimiento de las obligaciones internacionalmente asumidas.

2. Las significativas cláusulas de apertura internacional vehiculadas por la modificación constitucional de 1994 han sido realzadas operativamente por la jurisprudencia de la Corte Suprema, por caso, en punto a la existencia de la obligación en cabeza de los magistrados de realizar el control de convencionalidad -incluso de oficio- tomando en cuenta no sólo el contenido literal de la $\mathrm{CADH}$, sino la interpretación que de la misma ha realizado la Corte IDH.

3. El Tribunal exhibe, asimismo, sobre todo a partir de su actual conformación, una fuerte propensión a receptar en sus pronunciamientos los dictados del derecho internacional de los derechos humanos, tanto en lo que hace al respeto por las cláusulas de los instrumentos internacionales (incluso algunos de soft law) como a la interpretación de los órganos jurisdiccionales y cuasijurisdiccionales de supervisión de los distintos sistemas protectorios en la materia: interamericano (Corte IDH) y universales (Comité de los Derechos del Niño; Comité de Derechos Humanos; Comité de Derechos Económicos, Sociales y Culturales; Comité de Libertad Sindical y Comisión de Expertos en Aplicación de Convenios y Recomendaciones de la OIT) ${ }^{77}$.

No se ha limitado a concretarlo en materias primordialmente asociadas a los derechos civiles y políticos, sino también a los derechos de incidencia colectiva y a los derechos económicos, sociales y culturales ${ }^{78}$ (DESC), generando un aporte para eliminar los obstáculos que suelen impedir el goce real de estos últimos, que no tienen menor entidad que los civiles y políticos y, en consecuencia, no pueden quedar maniatados al influjo de un malentendido concepto de "progresividad", que no puede ser traducido como letargo o pasividad estatales indefinidos.

En materia de DESC, es capital tener en cuenta que sin perjuicio de que los avances deban ser progresivos, ellos cuentan a su favor con la prohibición de "regresividad". Es decir, que la línea de protección debe dirigirse hacia su mejoramiento paulatino, logros que a medida que se produzcan no pueden retrogradar o involucionar.

\footnotetext{
${ }^{77}$ Ver para ampliar, BAZÁN, Víctor, por ejemplo, "La interacción del derecho internacional de los derechos humanos y el derecho interno en Argentina", Estudios Constitucionales, Año 5, № 2, 2007, Centro de Estudios Constitucionales de Chile, Universidad de Talca, Santiago, pp. 137-183.

${ }^{78}$ Sobre el tema, compulsar BAZÁN, Víctor, v.gr., "La judicialización de los derechos económicos, sociales y culturales", en BAZÁN, Víctor (dir.), La judicialización de los derechos humanos, Sección Derechos Humanos de la Asociación Argentina de Derecho Internacional - Ediciones Legales, Lima, 2009, pp. 257-300.
} 
4. El balance de la línea de fallos del Tribunal en materia de protección de derechos fundamentales arroja un saldo positivo, según corresponda, por su impacto y debate sociales, por su carácter innovador o por su complejidad técnica. Asimismo se observa que la institucionalidad vigente en materia de justicia constitucional ha supuesto un avance en la protección de los derechos fundamentales.

5. Una de las claves para comprender la vinculación del derecho internacional y el derecho vernáculo radica en internalizar que la eficacia real del primero depende en buena medida de la fidelidad con que los derechos nacionales se conformen a las normas internacionales y les den efecto ${ }^{79}$.

Así, en la lógica interactiva del derecho internacional de los derechos humanos y el derecho interno que la CSJN debe manejar equilibradamente, siempre habrá de tener presente que la Constitución, con la magnitud normativa que le es inherente, y los instrumentos internacionales sobre derechos humanos conforman un cuerpo jurídico que orienta su vigencia hacia un idéntico sustrato axiológico: la protección y la realización de los derechos fundamentales, que son expresión directa de la dignidad humana.

\section{BiBLIOGRAFÍA}

BAZÁN, Víctor (2009): "La judicialización de los derechos económicos, sociales y culturales", en BAZÁN, Víctor (director), La judicialización de los derechos bumanos (Sección Derechos Humanos de la Asociación Argentina de Derecho Internacional - Ediciones Legales, Lima, pp. 257-300).

BAZÁN, Víctor (2008): "El derecho a la vida privada y el derecho a la libertad de información en la doctrina y jurisprudencia de la Corte Suprema de Justicia argentina", Estudios Constitucionales, Año 6, No 1 (Centro de Estudios Constitucionales de Chile, Universidad de Talca, Santiago, pp. 103-154).

BAZÁN, Víctor (2007): "La interacción del derecho internacional de los derechos humanos y el derecho interno en Argentina", Estudios Constitucionales, Año 5, No 2, 2007 (Centro de Estudios Constitucionales de Chile, Universidad de Talca, Santiago, pp. 137-183).

BAZÁN, Víctor (2003): Jurisdicción constitucional y control de constitucionalidad de los tratados internacionales. Una visión de derecho comparado (Porrúa, México, D.F.).

BAZÁn, Víctor (2000): "La Convención Americana sobre Derechos Humanos y el efecto de las reservas respecto de su entrada en vigencia: a propósito de la

${ }^{79}$ Cfr. Pastor Ridruejo, José A., op. cit., p. 165. 
O.C.-2/82 de la Corte Interamericana de Derechos Humanos", en BIDART CAmpos, Germán et al. (coordinadores), T. I (Ediciones Jurídicas Cuyo, Mendoza, pp. 91-165).

Carrillo Salcedo, Juan A. (1994): Curso de Derecho Internacional Público. Introducción a su estructura, dinámica y funciones, $1^{\mathrm{a}} \mathrm{ed}$., 2a reimpres. (Tecnos, Madrid).

GeLLI, María Angélica, "El terrorismo y el desarrollo progresivo de un delito internacional”, La Ley, T. 2005-E (Buenos Aires, pp. 1179-1180).

Díez de Velasco Vallejo, Manuel (1988): Instituciones de Derecho Internacional Público, T. I, 8 a ed., (Tecnos, Madrid).

Pastor Ridruejo, José A. (2006): Curso de Derecho Internacional Público y Organizaciones Internacionales, $10^{\mathrm{a}} \mathrm{ed}$. (Tecnos, Madrid).

Verdross, Alfred (1927): "Le Fondement du Droit Internacional", Recueil des Cours de l'Académie de Droit Internacional de La Haye, I, vol. 16. 
